Lepr Rev (2000) 71, 144-153

\title{
Relapses in multibacillary leprosy patients: effect of length of therapy
}

\author{
B. K. GIRDHAR, ANITA GIRDHAR \& ANIL KUMAR \\ Central JALMA Institute for Leprosy, Taj Ganj, Agra 282001, India
}

Accepted for publication 11 April 2000

\begin{abstract}
Summary Two groups of MB leprosy patients, one treated to the point of smear negativity (TSN) and the other given therapy for fixed duration (24 doses of WHO MB regimen) (FDT), were compared for relapse rates during treatment and in the posttreatment period. During the follow-up of $980 \cdot 2$ person years in 260 patients treated with FDT, 20 relapses (2.04/100 patient years) were observed. In the other group of 301 patients, who received therapy till smear negativity, 12 relapses in 1085.46 person years (1.10/100 patient years) occurred. Comparison of survival rates (without relapse) has shown that although there is no difference up to 4 years, the risk of relapse was significantly higher on longer follow-up in the FDT group. In addition, when patients were compared on the basis of initial bacterial load, it was found that the relapse rates in patients with $\mathrm{BI} \geq 4$ was significantly higher $(P<0 \cdot 01)$ in the FDT group as compared to those receiving treatment till the point of smear negativity (4.29 versus $1.27 / 100$ patient years). All the relapsed patients responded to retreatment with the same drug combination, indicating that the exacerbation in their condition was because of insufficient treatment. It is suggested that to prevent or reduce relapses, treatment where feasible would be continued till smear negativity, at least in patients with high BI.
\end{abstract}

\section{Introduction}

Multi-drug therapy (MDT) was introduced in the treatment of leprosy in the 1980s and since then there has been a significant change in leprosy scenario both at the global and the national level. More than 8.4 million patients had been cured by MDT up to the beginning of $1997 .{ }^{1}$ In India, the caseload of active patients has come down to less than 0.6 million from an earlier estimate of about 5 million, with many leprosy related parameters also having shown a downward trend. ${ }^{2}$ This has been attributed to the high efficacy of MDT, in addition to increased political commitment and better supervision in the field. The early results with the use of drug combinations have been generally good, with very few practical problems. ${ }^{3}$

The success with MDT administered to the point of negativity in MB patients has encouraged workers to test shorter regimens of 2 years and even 12 months. The observation of continued clinical improvement and fall in BI, even after stoppage of treatment at the end 
of 2 years, and no relapses in the follow-up period, ${ }^{4,5}$ resulted in 2 years fixed duration treatment (FDT) being recommended for field therapy of leprosy patients throughout the world. ${ }^{6}$ Thus, FDT has been the mainstay of treatment of MB patients for the last 4-5 years and has been applied to all MB patients, irrespective of bacterial load and classification.

As in tuberculosis chemotherapy, in leprosy too, it is considered that the magnitude of relapses in the post-treatment follow-up period is an important parameter of efficacy and robustness of the regimen. Very low relapse rates in MB patients have been reported in several field studies carried out in different parts of the world. ${ }^{1,3}$ However, of late, patients with relapses have been seen in many centres. ${ }^{7-9}$

MDT has been practised in the Central Jalma Institute for Leprosy, Agra. A large caseload of MB patients has provided an opportunity to study their response to MDT. In a prospective study, long-term follow-up after MDT has been made with the aim of detailing the course and progress of patients, and studying relapses, if any. An attempt has been made to delineate factors associated with occurrence or non-occurrence of relapses in the two groups of $\mathrm{MB}$ patients, one given FDT (for 2 years) and the other treated with the same regimen but up to the point of smear negativity (TSN).

\section{Materials and methods}

The study was conducted in two parts in a sequential manner. In one, the FDT group, 370 previously untreated $\mathrm{MB}$ patients who received 24 monthly doses of MB treatment, as recommended by $\mathrm{WHO}^{6}{ }^{6}$ were included. The group included active IL, BL, BB and BT patients. Only those BT patients who were smear positive were included in the study group. A total of 287 patients took regular treatment and completed 24 doses within the stipulated 36 months. Of these, 260 were available to follow-up. Twenty-seven were lost to follow-up for reasons such as other illnesses (e.g. tuberculosis), migration or death due to other causes. The age of patients varied from 14 to 62 years (mean 39.1 $\pm 13 \cdot 2$ ); there were 242 males and 18 females. Patients had had their disease from 9 months to 7 years (mean $2.7 \pm 1.4$ years). Their disease classification and smear positivity, i.e. initial BI, is shown in Table 1. The smears were taken from four sites initially, during treatment and follow-up. Smears were repeated from the same four sites every 6 months during treatment and follow-up. However, when fresh lesions were suspected, these sites were included for smears. The mean of the four sites was taken as BI. All patients, while on treatment and after completion of FDT, were reviewed at least twice a year for clinical activity and bacteriological status.

The second part of the work comprised follow-up of 380 untreated lepromatous (BL/LL) patients in whom MDT had been given till smear negativity. A total of 301 patients were available for follow-up. The remaining 79 could not be followed up because of reasons such as migration or death. Their ages ranged from 13 to 59 years $(34 \cdot 5 \pm 15 \cdot 7)$. There were 30 females and the rest were males. The mean duration of illness in these patients was $3.82 \pm 2.79$ years. Mean BI, as detailed above, of more than 4 was observed in 210 patients, while 48 smears had a BI of 3.01-4.0 and the remaining 43 had a relatively low bacterial load with $\mathrm{BI}<3$. As stated, these patients had also been regularly monitored both during treatment, which was continued till smear negativity and in the post-treatment period. All patients of both groups, except one, had been clinically reviewed at least twice a year and smears repeated at least once a year during the follow-up period. For those patients who relapsed, the length of follow-up was taken up to the day of diagnosis of relapse. 
In the present study, relapse was defined as increase of at least $2 \log$ units BI at any site with or without the appearance of fresh lesions. Apart from the four sites as above, suspicious fresh lesions or suspicious erythema/infiltration was preferred for smears. Care was taken to differentiate relapse from reaction. Apart from insidious onset, asymptomatic nature, absence of systemic signs, increase in BI and lack of response to steroids were taken as criteria of relapse. If the lesions appeared suddenly, were associated with systemic symptoms or peripheral oedema and showed response to steroids, it was considered to be reaction and not relapse.

Statistical analysis was done using SPSS software and the K-M method of survival analysis was used for the two groups. Comparison of survival (without relapse) rates at different periods of observation (duration of treatment and follow-up) was done ${ }^{10}$ to assess statistical significance.

\section{Results}

FIXED DURATION THERAPY (FDT) GROUP

As shown in Table 1, $162(62.3 \%)$ patients in the group were of BL/LL type and 107 (41.2\%) had a bacterial load of 4 or more. On completion of 2 years therapy, 120 of the $260(46 \cdot 2 \%)$ patients had become smear negative (Table 2). A larger proportion, 71.2\% (109 of 153), of patients with $\mathrm{BI}$ of 3 or less had become negative in contrast to only 10.3\% (11 of 107) of

Table 1. Bacterial load and classification of patients given FDT

\begin{tabular}{lrrrr}
\hline & BI & BULL & BB & BT \\
\hline$\geq 4$ & 58 & 0 & 0 & 58 \\
$3 \cdot 01-4$ & 47 & 2 & 0 & 4 \\
$2 \cdot 01-3$ & 32 & 2 & 8 & 42 \\
$1 \cdot 01-2$ & 25 & 5 & 27 & 57 \\
$>0-1$ & 0 & 2 & 52 & 54 \\
Total & 162 & 11 & 87 & 260 \\
& & & & \\
\hline
\end{tabular}

Table 2. Progress of patients: time to reach smear negativity in FDT group

\begin{tabular}{|c|c|c|c|c|}
\hline \multirow[b]{2}{*}{ BI } & \multirow[b]{2}{*}{ No. of patients } & \multicolumn{2}{|c|}{$\begin{array}{c}\text { Patients who } \\
\text { became smear } \\
\text { negative at } 2 \text { years }\end{array}$} & \multirow{2}{*}{$\begin{array}{c}\text { Time to become smear } \\
\text { negative (months) } \\
\text { [mean } \pm \text { SD (range)] }\end{array}$} \\
\hline & & No. & $\%$ & \\
\hline$\geq 4$ & 58 & 4 & $6 \cdot 9$ & $50 \cdot 1 \pm 11 \cdot 4(42-76)^{*}$ \\
\hline $3 \cdot 01-4$ & 49 & 7 & $14 \cdot 3$ & $44 \cdot 3 \pm 8 \cdot 2(33-75)$ \\
\hline $2 \cdot 01-3$ & 42 & 16 & $38 \cdot 1$ & $38 \cdot 2 \pm 5 \cdot 3(31-47)$ \\
\hline $1 \cdot 01-2$ & 57 & 39 & $68 \cdot 4$ & $17 \cdot 0 \pm 2 \cdot 2(13-25)$ \\
\hline$>0-1$ & 54 & 54 & 100 & $8 \cdot 0 \pm 1 \cdot 2(6-15)$ \\
\hline Total & 260 & 120 & $46 \cdot 2$ & \\
\hline
\end{tabular}

*Three continued to be positive even at the end of 8 th year. 
Table 3. Details of relapses in patients given FDT

\begin{tabular}{|c|c|c|c|c|c|c|}
\hline \multirow[b]{2}{*}{ BI } & \multirow{2}{*}{$\begin{array}{c}\text { No. of } \\
\text { patients }\end{array}$} & \multirow{2}{*}{$\begin{array}{l}\text { Person-years } \\
\text { follow-up }\end{array}$} & \multicolumn{2}{|c|}{ Relapses } & \multicolumn{2}{|c|}{ Relapsed patients } \\
\hline & & & No. & Rate/100 PY & Classification & Presentation \\
\hline$\geq 4$ & 107 & $419 \cdot 2$ & 18 & $4 \cdot 29$ & $\begin{array}{l}\text { LL-13 } \\
\text { BL-4 } \\
\text { BB-1 }\end{array}$ & $\begin{array}{l}\text { Fresh lesions } 4 \\
\text { Fresh infiltration } 7 \\
\text { ENL } 1 \\
\text { Smear +ve } 6\end{array}$ \\
\hline$<4$ & 153 & 561 & 2 & $0 \cdot 36$ & $\begin{array}{l}\text { BB-1 } \\
\text { BT-1 }\end{array}$ & Reversal reaction 2 \\
\hline Total & 260 & $980 \cdot 2$ & 20 & $2 \cdot 04$ & $\begin{array}{l}\text { LL-13 } \\
\text { BL-4 } \\
\text { BB-2 } \\
\text { BT-1 }\end{array}$ & \\
\hline
\end{tabular}

highly bacillated patients $(\mathrm{BI}>4)$, showing complete clearance of bacilli. Follow-up after treatment stoppage revealed that even 6 years later, eight patients (all BL/LL with BI >4) were still positive and three of them continued to be positive even after 8 years of therapy. All other high BI patients showed a gradual decline in skin smear positivity, the BI coming down by $0.5-0.9 \log$ units per year. Of the BT and BB patients, nine patients (all with initial BI of $<2$ ) continued to have active lesions for 1-3 years after completion of treatment, even though they had become smear negative in 12-18 months.

A total of 46 patients in this group developed reactions. Of the $19 \mathrm{BL} / \mathrm{LL}$ patients who had reactions, 12 had ENL and seven reversal reaction Two of the 19 had motor deficit. The remaining 27 with reaction were borderline leprosy (BB/BT) patients Six had more than one episode of reversal reaction. In 14 patients both skin and nerves were affected in reaction. Eight of the borderline patients had motor deficit. The patients were managed with thalidomide and those with reversal reactions given steroids, respectively, and all but five responded well. Of the five problem patients, three had recurrent ENL while in two, motor recovery was not complete.

Periodic examination over the next 2-8 years was done and each patient, except one, was seen at least twice a year. Follow-up of 980.2 patient years $(3.77 \pm 0.82)$ revealed that 20 had worsened bacteriologically, as evidenced by an increase in BI of more than 2 log units $(2+)$ over the last reading, with or without clinical deterioration. This was taken as indicating relapse, giving an overall relapse rate of 2.04/100 patient years (or $7.7 \%$ during 3.7 years mean follow-up). Details of these are given in Table 3. Among the patients with $\mathrm{BI} \geq 4,18$ relapses (4.29/100 patient years) were observed. Two relapses $(0 \cdot 36 / 100$ patient years) were found in patients with $\mathrm{BI}<4$, one each in patients with $\mathrm{BB}$ and $\mathrm{BT}$ leprosy. The relapse rate was thus significantly higher in patients with $\mathrm{BI} \geq 4(P=0.0002)$. Of the total relapses, 17 occurred within the first 3 years of follow-up and the remaining three more than 5 years after stopping treatment.

In 11 of the relapsed patients, there was clinical evidence in form of fresh lesions (papules, plaques or infiltration), while in three, reaction (reversal reaction in two and ENL in one) was the first manif estation. Six patients were with relapse when smears showed a higher BI without any clinical signs. All the relapsed patients responded to reintroduction of the same MDT regimen (plus thalidomide or steroids in cases of reactions) and showed clinical regression and smear negativity within 2 years of restart of treatment. 
Table 4. Length of treatment in BL/LL patients treated up to smear negativity

\begin{tabular}{|c|c|c|c|}
\hline \multirow[b]{2}{*}{ Treatment in years } & \multicolumn{3}{|c|}{ Patients who became smear negative } \\
\hline & No. & $\%$ & Cumulative $\%$ \\
\hline$<4$ & 88 & $29 \cdot 23$ & $29 \cdot 23$ \\
\hline $4-5$ & 94 & $31 \cdot 23$ & $60 \cdot 40$ \\
\hline $5-6$ & 86 & $28 \cdot 57$ & $89 \cdot 03$ \\
\hline$>6$ & 33 & $10 \cdot 96$ & $100 \cdot 00$ \\
\hline
\end{tabular}

Duration of treatment for smear negativity (mean) $4.9 \pm 2.3$ years.

TREATMENT TO POINT OF SMEAR NEGATIVITY (TSN)

As expected, in a majority of patients the treatment had to be continued for a long time. Details of length of treatment required to reach bacteriological negative state are shown in Table 4. The mean time taken to become smear negative was $4.9 \pm 2.3$ years. During treatment, reactions occurred in 116 patients (ENL in 105 and RR in 11, with two having both together).

A follow-up of 1085.46 years (mean 3.6 years) had been made in this group (Table 5). In the post-treatment period, though smear negative, nine patients suffered from ENL reactions. Eight had one episode of ENL, while the remaining patient had recurrent ENL. One patient had reversal reaction. During the follow-up, 12 relapses were seen. Thus, a relapse rate of $1 \cdot 11 / 100$ patient years ( $3.99 \%$ over 3.6 years mean follow-up) was observed. Ten relapses were diagnosed within 3 years of treatment stoppage. From Table 6, it is observed that 11 of the 12 relapses were in patients with initial large bacterial load $(B I \geq 4)$. Five of the 12 relapses were clinically silent and were detected on periodic smear examination, while four had fresh papules and in one, facial redness was the first sign. Two patients showed smear positivity when they came with ENL. All the relapsed patients were restarted on WHO MDT and 10 who continued treatment showed good response and became smear negative in 5-24 months, two having defaulted.

Table 5. Follow-up and relapses in patients treated till smear negativity

\begin{tabular}{lcccc}
\hline & & & \multicolumn{2}{c}{ Relapse } \\
\cline { 4 - 5 } $\begin{array}{l}\text { Follow-up } \\
\text { (in months) }\end{array}$ & Patients & $\begin{array}{c}\text { Person years } \\
\text { follow-up }\end{array}$ & No. & Rate/100 PY \\
\hline$<24$ & 68 & $109 \cdot 05$ & 7 & $6 \cdot 42$ \\
$25-36$ & 61 & $174 \cdot 15$ & 3 & $1 \cdot 72$ \\
$37-48$ & 84 & 323.47 & 1 & $0 \cdot 31$ \\
$49-60$ & 67 & 321.24 & 1 & $0 \cdot 31$ \\
$>60$ & 21 & $157 \cdot 56$ & 0 & $0 \cdot 31$ \\
Total & 301 & $1085 \cdot 46$ & 12 & $1 \cdot 11$ \\
\hline
\end{tabular}


Table 6. Details of relapses in patients treated up to smear negativity

\begin{tabular}{|c|c|c|c|c|c|c|}
\hline \multirow[b]{2}{*}{ BI } & \multirow{2}{*}{$\begin{array}{l}\text { No. of } \\
\text { patients }\end{array}$} & \multirow{2}{*}{$\begin{array}{l}\text { Person-years } \\
\text { follow-up }\end{array}$} & \multicolumn{2}{|c|}{ Relapses } & \multirow[b]{2}{*}{ Classification } & \multirow[b]{2}{*}{ Presentation } \\
\hline & & & No. & Rate/100 PY & & \\
\hline$\geq 4$ & 258 & $866 \cdot 45$ & 11 & $1 \cdot 27$ & $\begin{array}{l}\text { LL-8 } \\
\text { BL-3 }\end{array}$ & $\begin{array}{l}\text { Fresh papules } 3 \\
\text { Facial redness } 1 \\
\text { ENL } 2 \\
\text { Smear +ve } 5\end{array}$ \\
\hline$<4$ & 43 & $219 \cdot 01$ & 1 & 0.46 & LL-1 & Fresh papule 1 \\
\hline Total & 301 & $1085 \cdot 46$ & 12 & $1 \cdot 1$ & $\begin{array}{l}\text { LL-9 } \\
\text { BL-3 }\end{array}$ & \\
\hline
\end{tabular}

\section{Discussion}

Field application of MDT in leprosy has been in progress for only 10-12 years and FDT for MB patients for even shorter duration of 4-5 years. Thus, follow-up of treated patients has not been long enough. Though early studies with short-term follow-up have shown good response, it is the long-term outcome of the treated patients that determines the ultimate utility of the therapeutic regimens. In leprosy, this has been possible in only a few centres.

Another aspect has been the continuously changing definition of MB patients. Initially only smear positive patients with BI $>2$ at any site belonging to BT and all active patients with $\mathrm{BB}, \mathrm{BL}$ and LL classification were included in the $\mathrm{MB}$ group. ${ }^{11}$ In view of the shortcomings in skin smear facilities at the field level, the definition was later modified to include all AFB positive patients of BT (irrespective of $\mathrm{BI}$ ) in addition to others. ${ }^{12}$ Subsequently, the MB group was enlarged to include all BT patients with more than five lesions as per WHO guidelines ${ }^{1}$ and $>10$ lesions as suggested by NLEP, India. ${ }^{13}$ Thus, in contrast to earlier studies on efficacy of MB treatment for multibacillary leprosy, the later ones include a substantial proportion of smear negative and/or low BI patients. Therefore, the outcome of recent studies is not comparable with initial trials in MB patients. In the present investigation, as was in practice at the time of start of work, only smear positive borderline (BT/BB) and lepromatous (BL/LL) patients have been taken.

The present study conducted with the aim of comparing the outcome of two regimens, differing in duration of treatment, primarily compares the number of relapses in two groups. For this, a uniform definition of relapse, as above, has been used. It is common observation that a significant proportion of MB patients, at the end of 2 years of FDT, are still smear positive and this is especially true for patients with BI on the higher side. Therefore, for diagnosis of relapse an increase in BI has been taken as the main criterion. For this, patients have been regularly followed up and examined at least twice a year and skin smears repeated. BI was compared with ears, earlier lesions or surrounding skin as the case may be. During follow-up, in patients who showed higher BI on one or more sites without any fresh or active lesion, repeat smears were done and assessed independently for confirmation. Because of certain problems, inoculation of mice could not be done for confirmation of viable organisms and drug susceptibility. However, response to repeat MDT, with same drug combination has been studied and taken as indirect evidence of both the viability and the susceptibility of M. leprae to drugs used as components of MDT. 
The study has shown that in the group which was given FDT, there were 20 relapses in a follow-up period of $2-8$ years (mean $3 \cdot 77 \pm 0.82$ ), giving a relapse figure of $2 \cdot 04 / 100$ patient years (or $7 \cdot 69 \%$ over a $3 \cdot 75$-year follow-up, approximately). The denominator here includes $87 \mathrm{BT}$ and 11 borderline patients. Of these 98 patients, only three relapsed (relapse rate $=$ $0 \cdot 53 / 100$ patient years), suggesting that therapy (2 years FDT) was adequate. Of the remaining 162 patients, all of whom belonged to the BL/LL group, 17 (10.5\%) relapsed during the surveillance period, showing a significantly higher relapse rate as compared to $\mathrm{BB} /$ BT $(P<0.02)$. Of the total 20 relapses, 18 initially had a high BI of $\geq 4$. In addition, all of them (18 patients) had a BI of $>3+$ at the time of RFT, i.e. after 24 doses. Thus, in the group with high initial BI, a relapse rate of $4 \cdot 20 / 100$ patient years (overall $16.8 \%$ ) was observed, which is significantly higher than in the group with $\mathrm{BI}<4(P=0.0002)$. This indicates that within the MB group, patients differ in their response to treatment. While BT/BB patients and those with $\mathrm{BI}<4$ respond well, treatment seems to be inadequate for patients with a large bacterial load, mostly those with B/LLL disease.

A total of 46 patients developed reactions during the above follow up period; 34 had reversal reaction (seven BL/LL, $27 \mathrm{BT} / \mathrm{BB}$ ) and the remaining had ENL. All belonged to the BL/LL group. The frequency is much higher than observed in field programmes. This is possibly on account of the larger proportion of patients continuing to be smear positive and may also be the result of clofazimine withdrawal on completion of FDT. There was no difference in the proportion of patients relapsing among patients with or without reactions in the post-treatment follow-up. Because of early diagnosis and management, very few patients, only two, had residual motor weakness. The observation of eight patients developing ENL in the post-treatment period highlights the fact that a significant proportion of patients with smear positivity, at the point of RFT, are likely to get reactions, and this therefore necessitates their regular follow-up at least to the point of their becoming smear negative. Further, detailed instructions to patients to visit the clinic early, if problems occur, can help in preventing deformities by early institution of anti-reaction treatment.

In the TSN group, of the 301 patients about 90\% became negative in 6 years; the mean time for the smears to become negative was $4.9 \pm 2.3$ years (Table 4). Comparison of the decrease in BI in the two groups of the present study shows that the fall in the bacterial load appears similar, confirming that bacillary clearance is not affected by continued administration of the drugs (data not shown). Patients have been followed from 9 months to over 7 years after treatment stoppage. The occurrence of 12 relapses (Table 6) during the observation period gives a relapse rate of $1 \cdot 10 / 100$ patient years (or $3.99 \%$ over a mean follow-up period of 3.6 years). Here also, the majority of relapses were recorded within 3 years of treatment stoppage after smear negativity.

Periodic smear examination was found to be useful for detection of exacerbation, as this alone resulted in relapse diagnosis in five patients. One of the patients who attended the clinic after a default of 4 years, though clinically well, was found to be smear positive (3+) from the flank region, while smears from other sites were negative. Clinical signs of relapse were found in five and ENL as the first manifestation in two patients. Of the 12 relapses seen in the TSN group, 11 were among the patients with $\mathrm{BI} \geq 4$ (Table 6) and occurred during the follow-up period of 866.45 patient years, giving a relapse rate of $1 \cdot 27 / 100$ patient years. This indicates that among patients treated up to the point of negativity, the relapse rate as in EDT, was more in patients with $\mathrm{BI} \geq 4$ than those with smaller bacterial load, though the difference within the TSN group was not significant. When compared, with patients given FDT, the 
Table 7. Comparison of survival (without relapse) rates, in the two treatment groups

\begin{tabular}{|c|c|c|c|c|c|}
\hline \multirow{2}{*}{$\begin{array}{l}\text { Duration of } \\
\text { treatment \& } \\
\text { follow-up }\end{array}$} & \multicolumn{2}{|c|}{$\begin{array}{l}\text { Fixed duration therapy } \\
\text { (FDT) group }\end{array}$} & \multicolumn{2}{|c|}{$\begin{array}{l}\text { Up to smear negative } \\
\text { group }\end{array}$} & \multirow[b]{2}{*}{$P$-value } \\
\hline & $\begin{array}{c}\text { Cumulative } \\
\text { survival }\end{array}$ & SE & $\begin{array}{l}\text { Cumulative } \\
\text { survival }\end{array}$ & SE & \\
\hline 36 & 0.9960 & 0.0040 & 0.9965 & 0.0035 & 0.94 \\
\hline 48 & 0.9874 & 0.0072 & 0.9965 & 0.0035 & $0 \cdot 267$ \\
\hline 60 & 0.9731 & 0.0108 & 0.9965 & 0.0035 & 0.047 \\
\hline 84 & $0 \cdot 8973$ & 0.0250 & 0.9623 & 0.0071 & $0 \cdot 0188$ \\
\hline 96 & 0.8500 & 0.3275 & 0.9536 & 0.0131 & 0.0055 \\
\hline 120 & $0 \cdot 8121$ & 0.0409 & 0.9369 & 0.016 & 0.0067 \\
\hline
\end{tabular}

relapse rate is lower among who had been treated till the smear negativity (2.04 versus $1 \cdot 10$ / 100 patient years). Survival analysis has been done to compare relapse rates in the two treatment groups (Table 7, Figure 1). Comparison of survival (without relapse) has been made up to 10 years, including the initial period of treatment (2 years in FDT and till smear negativity in the other group). There was no difference in the risk of relapse up to the fourth year; however, subsequently the hazard (relapse) risk was significantly higher in the EDT group, especially on longer follow-up. The difference is likewise larger when comparison is made of high BI patients in the two groups (4.29 in EDT versus 1.27/100 patient years in the

FDT vs TSN

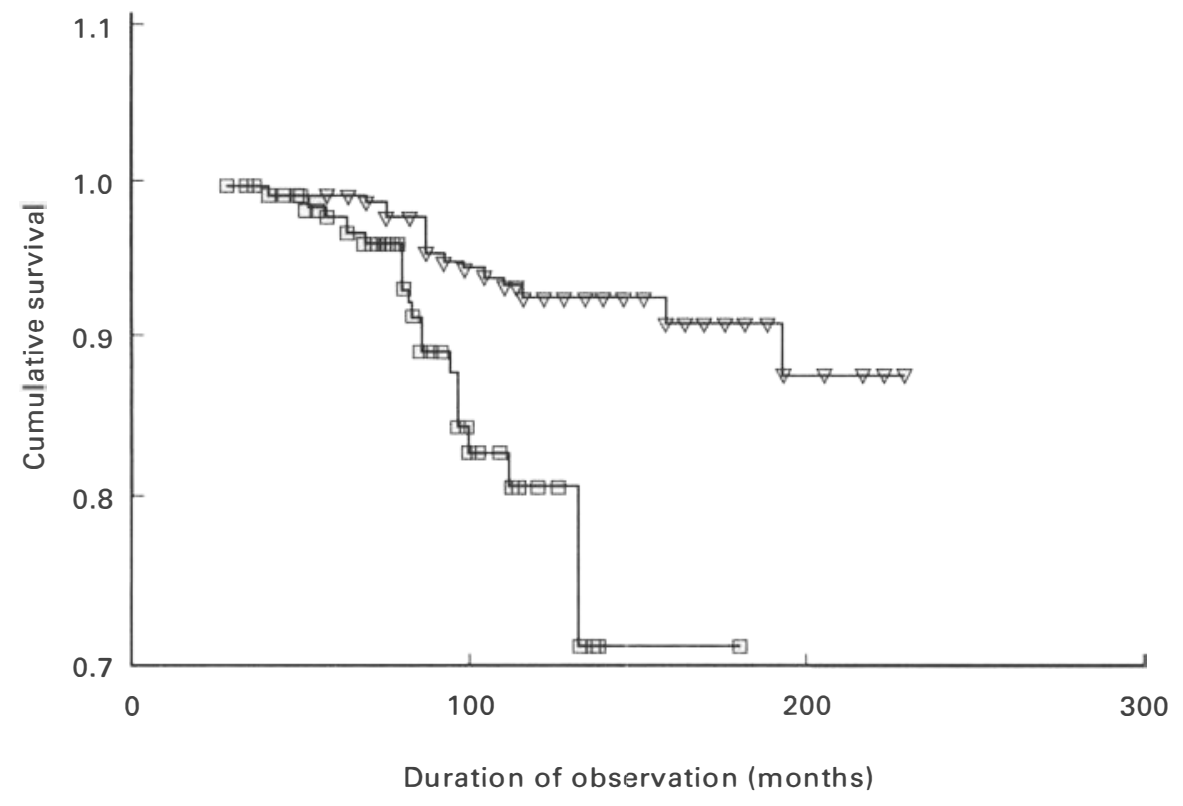

Figure 1. Comparison of survival (without relapse) rates in two treatment groups, FDT ( $\square$ ) and TSN ( $\nabla)$. 
TSN group) and this difference was statistically significant $(P<0 \cdot 01)$. This indicates that relapses are fewer when longer treatment up to smear negativity is given and that the initial bacterial load, as well as BI, at the end of 2 years (figures not shown), is well correlated with relapses. This offers an explanation for the low relapse rates in many of the field studies, wherein the MB group of borderline patients who have been taken in on the basis of a larger number of lesions and/or are only marginally smear positive. Another explanation could be a better follow-up and periodic smears done in these trial groups as compared to the field studies, apart from the fact that the study was focused on the issue. Unlike, the report of Jamet et al. ${ }^{14}$ fewer relapses have been seen, even though there were larger numbers of patients with high BI in both the cohorts. This may be because of the relatively shorter follow-up in the present trial. Based on their experience ${ }^{14}$ that number of relapses goes up steeply with increasing length of follow-up and projection of hazard risk, patient are being kept under surveillance.

From the satisfactory outcome of retreatment with same drugs, it can be concluded that the relapses were a result of persistence of drug-sensitive organisms which might have escaped the action of drugs, as has earlier been shown in both THELEP studies ${ }^{15}$ and in our own work. ${ }^{16}$ Higher relapse rate in the 2 year FDT group could therefore mean that not enough therapy had been given to kill all the organisms. This is in line with Pattyn's suggestion ${ }^{17}$ that relapses in leprosy are biphasic, early relapses resulting from inadequate therapy while the late relapses may be the outcome of reactivation of persisters or reinfection. Indeed, our observations point to the relative earlier occurrence of relapses. It can be seen that in 15 of the 18 relapses in high BI $(\geq 4)$ patients in the FDT group and in 10 of the 12 longterm treatment patients, relapses occurred within 4 years of stopping treatment, suggesting that therapy was not able to kill all the viable organisms.

The present study has shown that short course treatment (FDT), especially for high BI patients, is not adequate in reducing the relapses in the follow-up period, as earlier reported. ${ }^{13}$ Since a majority of relapses were in patients with $\mathrm{BI} \geq 4$, it would be better to continue treatment for a longer period, at least in this group. Since the BI in almost all patients had come down to $\leq 2$ by $4-5$ years, in highly bacillated patients treatment should be continued for another 2 years, as has been proposed by Waters. ${ }^{18}$ Thus, by the time they are released from treatment, the remaining number of bacteria will be small and the chances of any surviving $M$. leprae would be minimized. Since almost all high BI patients belonged to the BL/LL group, in places where smear facilities are not adequate, classification of patients could be taken as a guide. Thus fresh (untreated) patients with nodules, infiltration and/or numerous small symmetrically placed lesions and multiple symmetrically thickened nerves should receive longer treatment. In the field especially, where MDT activities have been going on for several years, the number of highly positive patients is not likely to be very large and therefore, a longer treatment for the few is feasible and should be considered. One may argue against this, as the relapses are due to drug (rifampicin, clofazimine and dapsone) sensitive organisms and could be retreated as and when they occur. However, when one considers the proportion in which relapses have been observed (Jamet et al. ${ }^{15}$ and this study) and the impact of treatment failure on acceptance of therapy, a policy and recommendation for longer treatment appears justified for the group of patients with higher bacillary load $(B I \geq 4)$. Further, in view of frequent reactions, periodic follow-up until the patients become smear negative must be continued, as it would not only be beneficial in reducing deformities but also help in early diagnosis of relapses, if they occur. 


\section{Acknowledgement}

The authors sincerely thank the paramedical staff and the clinical laboratory staff of the Institute for providing support to the work. Shri Santosh Masih's help in preparing the manuscript is gratefully acknowledged.

\section{References}

${ }^{1}$ World Health Organization. WHO Expert Committee on Leprosy, 7th report. WHO Technical Report No. 874, World Health Organization, Geneva, 1998.

2 Directorate General of Health Services. Goverment of India Guidelines on Modified MDT. Ministry of Health \& Family Welfare, Nirman Bhawan, New Dethi, India, 1997.

${ }^{3}$ Noordeen SK. A look at world leprosy. Lepr Rev, 1991; 62: 72-86.

${ }^{4}$ Ganapati R, Pal R, Gandewar KL, Thressia Xi. For how long should a multibacillary leprosy patient be treated. Ind $J$ Lepr, 1989; 61: 467-471.

5 Katoch K, Ramanathan U, Natrajan M. Clinical and bacteriological progress of highly bacillated BL-LL patients discontinuing treatment after different periods on MDT. Int J Lepr, 1991; 59: 248-254.

6 World Health Organization. Chemotherapy of leprosy. WHO Technical Report No.847, World Health Organization, Geneva, 1994

7 Van Brakel W, Kist P, Noble S, O'Toole L. Relapses after multidrug leprosy: a preliminary report of 22 cases in West Nepal. Lepr Rev, 1989; 60: 45-50.

8 Constant-Desportes M, Guelpa-Lauras CC, Carolina JC, Leoture A, Grosset JH, Sansaricq H. A case of relapse with drug-susceptible M. leprae after multidrug therapy. Int J Lepr, 1991; 59: 242-247.

9 Marchoux Chemotherapy Study Group. Relapses in multi-bacillary leprosy patients after stopping treatment with rifampicin containing combined regimens. Int J Lepr, 1992; 60: 525-535.

10 Le, Chap. T. Applied categorical data analysis. Wiley, New York, 1998.

11 World Health Organization. Chemotherapy of leprosy for control programmes. WHO Technical Report Series, No.675, World Health Organization, Geneva, 1982.

12 World Health Organization. WHO Expert Committee on Leprosy, 6th report. WHO Technical Report Series No. 768, World Health Organization, Geneva, 1988.

13 Leprosy Division, Directorate General of Health Services, National Leprosy Eradication Programme in India. Guidelines for multidrug treatment in non-endemic districts. Ministry of Health \& Family Welfare, Nirman Bhawan, New Delhi, India, 1994.

14 Jamet P, Ji B. Marchoux Chemotherapy Study Group. Relapses after long-term follow-up of multibacillary patients treated by WHO multidrug regimen. Int J Lepr, 1995; 63: 195-201.

15 Subcommittee on Clinical Trials of the Chemotherapy of Leprosy (THELEP), Scientific Working Group of the UNDP/World Bank/WHO Special Programme for Research and Training in Tropical Diseases. Persisting M. le prae among THELEP trial patients in Bomako and Chingleput. Lepr Rev, 1987; 58: 325-337.

16 Girdhar, BK, Sreevatsa XX, Girdhar A, Desikan KV. Multidrug therapy in lepromatous patients. Ind J Dermatol Venerol Leprol, 1984; 50: 240-244.

17 Pattyn SR, Groenen G, Bourland J. The incubation time of relapses after treatment of multibacillary leprosy with rifampicin containing regimens. Eur J Epidemiol, 1988; 4: 231-234.

18 Waters MFR. Relapse following various types of multidrug therapy in multibacillary leprosy. Editorial. Lepr Rev, 1995, 66: 1-9. 